\title{
Clinical outcomes after carbon-plate osteosynthesis in patients with distal radius fractures
}

\author{
Florin Allemann ${ }^{*}$ (D, Sascha Halvachizadeh, Thomas Rauer and Hans-Christoph Pape
}

\begin{abstract}
Background: Surgical implant material has changed over time, from metal to stainless steel to titanium. In recent decades a new material, carbon-fibre-reinforced polyether ether ketone, has been introduced. The aim of this study was to assess the clinical and radiological feasibility and functional outcome after treatment of distal radius fractures with this new implant.

Methods: Inclusion criteria: AO type B distal radius fractures treated with $2.7 \mathrm{~mm}$ CF/PEEK plates at one Level 1 trauma centre between 2016 and 2017. Follow-up period 1 year, measurement of range of motion and radiographic assessment, histological analysis of debris only after plate removal.

Results: Out of 112 eligible patients, 10 (8.9\%) patients were included. Mean operation time was $65 \pm 10$ min. Radiographic healing was confirmed by radiologists at 6 weeks follow-up. During one-year follow-up, no adverse events were reported and functionality and patients subjective satisfaction improved significantly $(p<0.05)$. Only one plate was removed, with no histological signs of inflammation or allergic reaction.

Conclusions: The $2.7 \mathrm{~mm}$ CF/PEEK plate osteosynthesis appears to be a reliable and safe implant for certain types of distal radius fracture. Assessment of fracture union is substantially more practical and functionality improved significantly over 1 year.
\end{abstract}

Keywords: Carbon implant, CF/PEEK plates, Plate osteosynthesis, Wrist fracture, Distal radius fracture

\section{Background}

Implant biocompatibility is a major safety issue in orthopaedic fracture care. Historically, there have been issues with materials that do not consist of certain metals or metal combinations [1]. Incompatibility may occur with a time delay after implantation. Specifically, early carbon implants for anterior cruciate ligament (ACL) replacements have led to issues of failure and local tissue irritation. Likewise, nonmetal implants have caused local inflammatory reactions that precluded them from further clinical use [2, 3]. Along with the improvements in material development, new implant combinations have been developed that appear to be safe for routine clinical use. In this way, polyether ether ketone (PEEK) has been added to carbon [4-6]. In previous clinical applications, CF/PEEK implants have been used successfully to cover osseous defects in neurosurgical patients $[7,8]$. They have been favoured due to their abilities to sustain plastic deformation and their ability to mimic anatomic structures in other fractures as well, e,g., of the distal radius [9]. Meanwhile, various implants have been developed for orthopaedic fracture care, such as intramedullary nails, angular stable plates [10], and bar-to-bar constructs for spinal surgery. However, due to the relative novelty of the implant material, there are only a limited number of articles investigating clinical and functional outcomes of carbon-plate osteosynthesis. Therefore, the aim of this study was three-fold:

1. To assess the clinical application of plate osteosynthesis using $2.7 \mathrm{~mm}$ CF/PEEK plates in acute distal radius fractures,

* Correspondence: florin.allemann@usz.ch

Department of Traumatology, University of Zurich, University Hospital Zurich, Raemistrasse 100, 8091 Zürich, Switzerland

(c) The Author(s). 2019 Open Access This article is distributed under the terms of the Creative Commons Attribution 4.0 International License (http://creativecommons.org/licenses/by/4.0/), which permits unrestricted use, distribution, and reproduction in any medium, provided you give appropriate credit to the original author(s) and the source, provide a link to the Creative Commons license, and indicate if changes were made. The Creative Commons Public Domain Dedication waiver (http://creativecommons.org/publicdomain/zero/1.0/) applies to the data made available in this article, unless otherwise stated. 
2. To analyse the radiographic outcome and fracture consolidation of distal radius fractures treated with $2.7 \mathrm{~mm}$ CF/PEEK implants, and

3. To compare the development of functional outcome during routine clinical follow-up.

\section{Methods}

\section{Ethical considerations}

This study follows the guidelines of Helsinki [11] and was conducted after the approval by the local Zürich ethics committee (Kantonale Ethikkommission Zürich, KEK number 2018-00146).

\section{Study population and design}

This retrospective cross-sectional cohort study included adult patients treated due to a distal radius fracture at one Level 1 trauma centre between 2016 and 2017. Inclusion criteria included: displaced distal radius fracture in need of surgical stabilisation; AO type B fractures; and complete data at one-year follow-up period. Exclusion criteria included: AO type $\mathrm{C}$ fractures; carpal instability requiring additional implants (screws or plates); open fractures; patients with genetic disorders affecting the musculo-skeletal system; oncology patients; and multiply injured patients. All patients were surgically treated by one surgeon (FA).

\section{Implant}

All patients were treated with a $2.7 \mathrm{~mm}$ CF/PEEK plate (Inc. Icotec, Altstätten, Switzerland). Its design is oriented towards the conventional $2.4 \mathrm{~mm}$ two-column titanium plates (De Puy/Synthes, West Chester, PA). The implant follows the principles of the three-column theory [12] and allows for monoaxial screw placement.

\section{Follow-up}

During the one-year follow-up period, patients received routine check-ups at 6 weeks, 12 weeks, and 1 year after surgery. The follow-up was performed exclusively by the treating surgeon. The follow-up included routine clinical examination, including range of motion (ROM), pain on exertion, neurological examination, subjective comfort of the patient, and routine radiographic examination. Any issue of biocompatibility or discomfort possibly related to the implant was addressed specifically.

\section{Implant removal and histology}

Implant removal was performed only if medically necessary (infection, neuro-muscular damage) or after the patient's explicit wish. During implant removal biopsies of the granulation tissue at the screw holes of the plate were taken for histological analysis. Histological analysis included haematoxylin and eosin (HE) staining, cell count for inflammatory cells, and allergic responsive cells. Further, the histological probes were analysed for carbon debris and possible cellular incorporation of carbon debris.

\section{Outcome measures}

The primary outcome was improvement in ROM 1 year after surgery. This was assessed during routine clinical follow-up visits and measured in degrees $\left(^{\circ}\right)$. Further outcome parameters were radiographic union and the safety and feasibility of the use of CF/PEEK implant for surgical treatment of the distal radius fracture.

\section{Statistics}

Continuous variables are displayed as means with standard deviation, and categorical variables as numbers and percentages. The progress of ROM was compared by Students t-test and corrected for multiple testing. Categorical variables were compared using the chi-square test. Figures were designed using GraphPad Prism version 8.1.2. for Windows (GraphPad Software, San Diego, CA, USA; www.graphpad.com). Statistical tests were preformed using R (R Foundation for Statistical Computing, Vienna, Austria. www.R-project.org).

\section{Results}

Out of 112 distal radius fractures, ten patients (8.9\%) were eligible and consented to be treated with a CF/ PEEK implant. All included patients completed the follow-up period. These patients were $53.3 \pm 16.6$ years old and the male/female ratio was 60:40.

\section{Perioperative course}

The mean time of surgery was $65 \pm 10 \mathrm{~min}$. During surgery, two screw head breakages occurred in two different patients. Those holes were left unmounted. No further surgery-associated complications were observed during the follow-up period. The CF/PEEK plates were placed correctly under the watershed line and all distal CF/ PEEK screws were positioned without affecting the extensor tendon pockets. Of note, there was intraoperative breakage of a screw head in two screws (case nos. 2 and 5) and the screw holes were left unmounted. This did not lead to any complications.

\section{Postoperative course}

There was no incidence of wound breakdown postoperatively. No secondary secretion or drainage was observed. All patients sustained the routine protocol for staged physical therapy and did not report any implant-associated issues at any time. There were no extensor tendon problems. Algodystrophy did not occur in any patient. 


\section{Radiographic outcome}

Healing was uneventful and was completed at 6 weeks in all patients (Fig. 1).

At 12 weeks (Fig. 2) and at 1 year (Fig. 3) there was no loss of reduction. No implant failure, screw breakage or loosening was observed. The radiolucent properties of the implant facilitated substantially the assessment of union.

\section{Follow-up}

Four male (age range: $32-66$ years) and six female (age range: $45-78$ years) patients were re-examined. There was no carpal tunnel syndrome at follow-up. Flexion increased significantly by a mean of $15 \pm 13.0^{\circ}, p=0.0004$. Extension increased by a mean of $26.7 \pm 16.3^{\circ}$. Radial abduction and ulnar abduction increased significantly by a mean of $10 \pm 8.4^{\circ}, p=0.003$ and $5.8 \pm 10.2^{\circ}, p<0.0001$. Pronation increased by $12.5 \pm 11.7^{\circ}$ and supination significantly by a mean of $8.3 \pm 5.2^{\circ}, p=0.004$. These changes are shown in Fig. 4.

\section{Histological analysis}

Histological analysis was performed in only one patient (10\%). None of the patients had any medical reason for implant removal. Only one patient wished the implant to be removed, since she did not want any foreign implant in her body. At the time of implant removal (1 year after implantation), the fracture was healed. The gross inspection during implant removal did not show any signs of inflammation, hyper-perfusion, or swelling. HE staining of granulation tissue revealed no increased numbers of inflammatory cells, no increased numbers of eosinophils, and no implant debris. The pathologists did not describe any adverse histological reactions or allergic reactions.

\section{Discussion}

CF/PEEK implants represent a new material for surgical treatment of fractures. Numerous studies have investigated preclinical properties and biomechanics of this material and showed advantages as well as disadvantages compared to other materials [13-15]. This study aimed to investigate the clinical application of CF/PEEK plates for distal radius fractures and concluded the following points:

1. CF/PEEK implants are a safe and reliable implant in the treatment of acute distal radius fractures (AO type B),

2. Radiographic assessment is easier due to the unique property of radiolucency of CF/PEEK implants, and

3. The functional outcome improves significantly 1 year after treatment with CF/PEEK implant.

Angular stable plating has revolutionised the treatment of distal radius fractures [16]. While loss of reduction has been a frequent problem in the era of conventional plating, this complication was reduced tremendously by

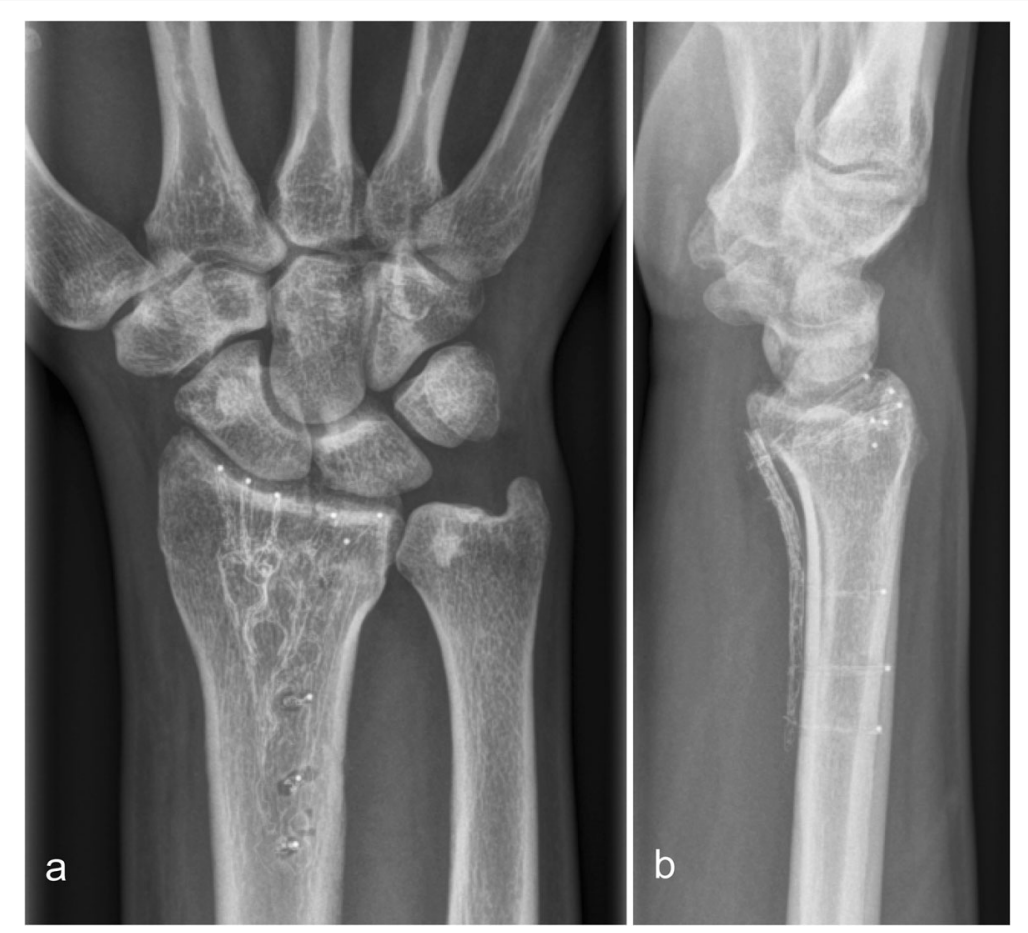

Fig. 1 Distal radius fracture treated with a $2.7 \mathrm{~mm}$ Carbon/PEEK plate. X-ray 6 weeks after surgery anteroposterior (ap) (a) and lateral (lat) view (b) 

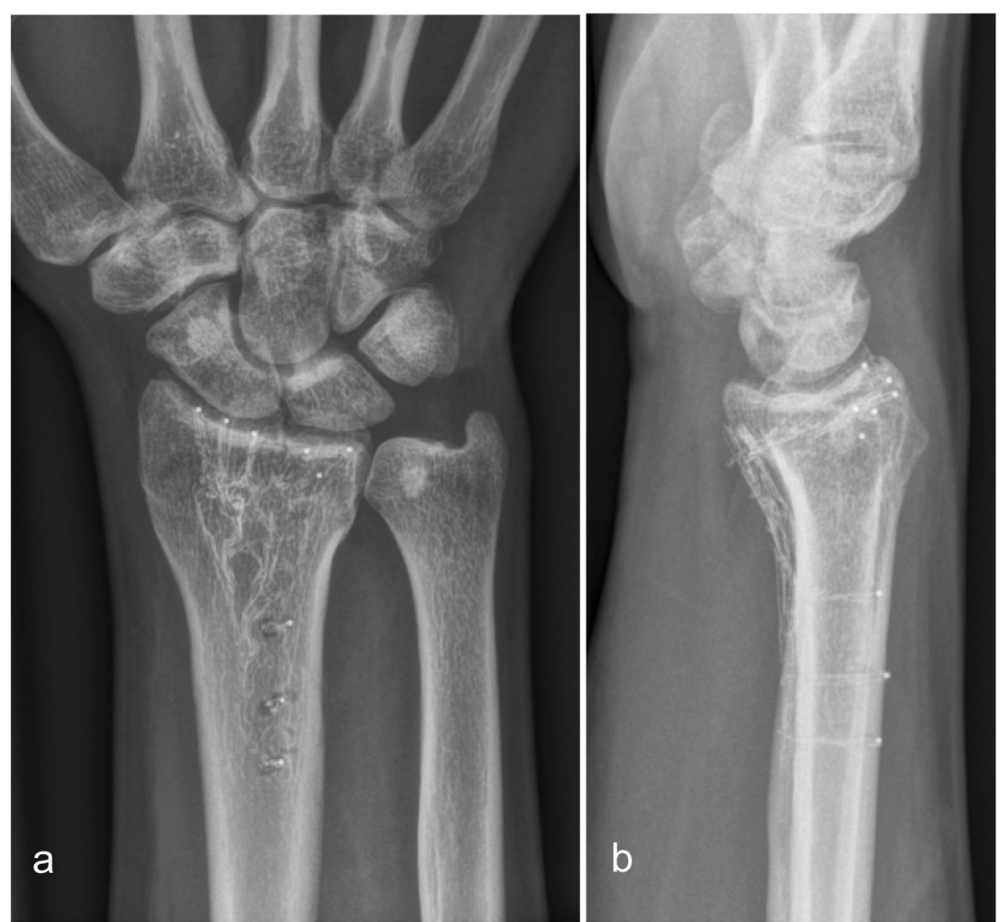

Fig. 2 Distal radius fracture treated with a $2.7 \mathrm{~mm}$ Carbon/PEEK plate. X-ray 12 weeks after surgery, ap (a) and lat view (b)

the use of volar angular plates [10]. Monoaxial screw fixation is usually sufficient in these situations as long as proper fracture reduction is achieved. Numerous studies have shown that volar supply also showed a good functional outcome in complex intra-articular fractures [17]. This could be dispensed with the additional supply of dorsal of complex distal radius fracture, and the frequent tendon injuries due to the compromise of the tendon pockets could be avoided. A new area began with the treatment of distal radius fractures with titanium plates and angle-stable screws. However, these developments also involved some difficulties.

Above all, three problem areas can be identified: First, due to metal artefacts one may not be able to evaluate osseous consolidation in some cases. This may result in more conventional X-ray controls; Second, metal artefacts in the immediate vicinity of the TFCC can aggravate a violation of this complex in terms of diagnostics; Third, the nature of titanium plates is not similar to that of natural bone. Conventional titanium plates are more rigid than biological bone [18]. In addition, plate design and screw thickness play essential roles in rigidity [19]. Studies with CF/PEEK implants show that this material has similar strength and rigidity to the titanium plates used today [20]. CF/PEEK is even closer to the biological properties of the bone structure.

In our series, monoaxial screws appeared to be sufficient for fixation of the intra-articular fractures selected; namely, AO type B injuries with no additional ulnar instability.

Our study has certain limitations. Certainly, the sample size was limited and the overall follow-up was around 1 year. However, we feel that despite the limited number, our study is valuable for the following reasons: 1. It represents a single-surgeon experience for surgery and two experienced surgeons for follow-up. 2. In all patients, we waited to submit the clinical result after completion of physical functioning and return to work. In distal radius fractures, this is achievable within 3 months after injury. 3. We were pleased with the radiolucency of the implant, allowing for proper assessment of healing in every X-ray on follow-up. In this respect, radius fractures differ from other injuries, such as tibial or femur shaft fractures.

In general, the individual functional score results and the mobility of the wrist joint demonstrated favourableto-excellent results in all cases, which are in accordance with other studies [21, 22]. Specifically, in the patients that had screw breakage intraoperatively, this did not result in clinical drawbacks. Since the screw breakage occurred in the first patients only, we feel that it represents the learning curve in dealing with a new type of implant. Regardless, in our series the general duration of surgery was comparable to that using conventional titanium implants. On re-examination, all patients were back to their regular activities and no limitations were observed. 


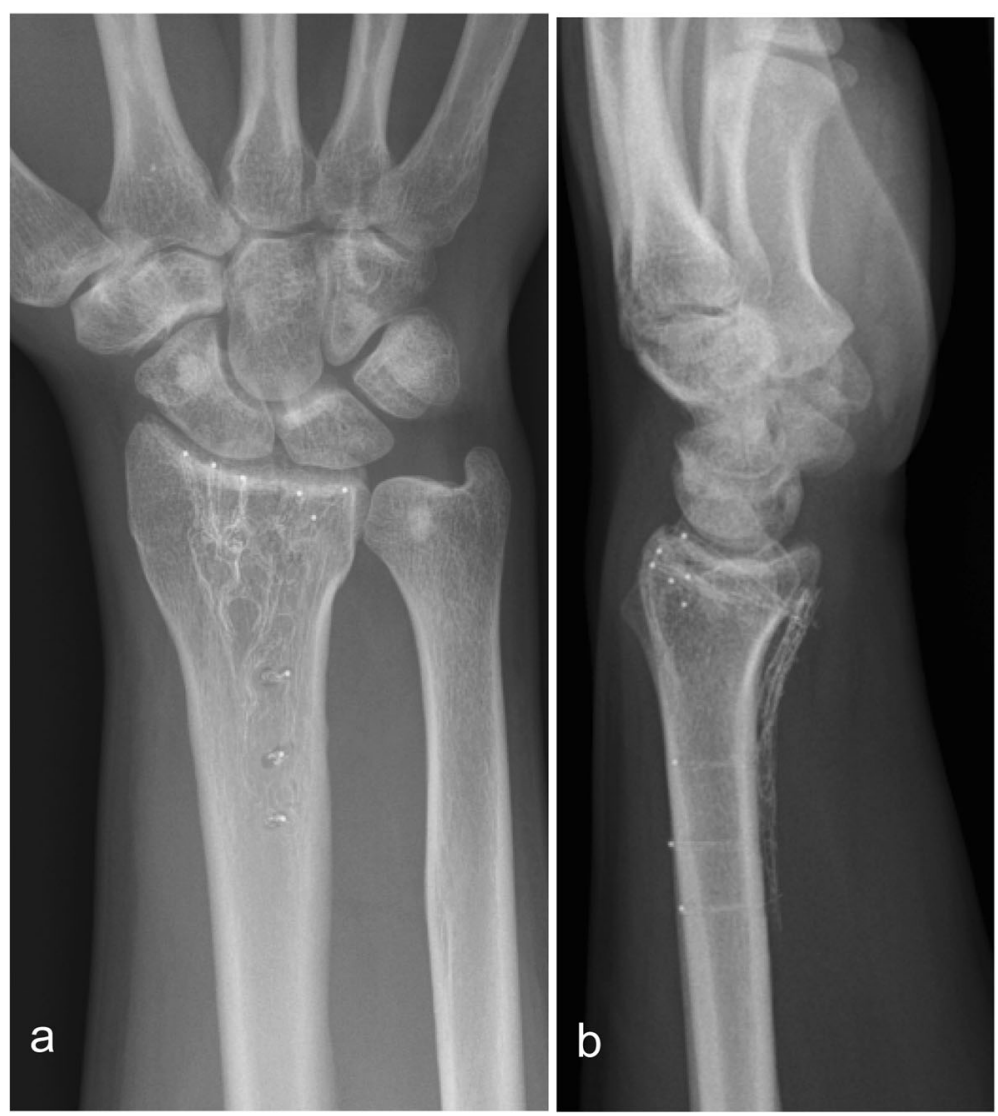

Fig. 3 Distal radius fracture treated with a $2.7 \mathrm{~mm}$ Carbon/PEEK plate. X-ray 1 year follow up ap (a) and lat view (b)

During follow-up, no patient reported problem in regards to the selected implant; namely, skin irritation, wound healing, signs of soft tissue irritation, swelling or redness. None of the patients developed implant-associated pain, infection, allergic reactions, or syndromes of neurological irritation, such as those described in carpal tunnel syndrome. There were no other clinical symptoms associated with wear of the implant, or other sign of wear.

In our results, none of the patients had any issue of bone healing, and the radiological assessment allowed for timely recovery in all cases. This is in line with $\mathrm{Di}$ Maggio's results [23]. The authors examined patients with CF/PEEK implants and pointed out that CF/PEEK allows for assessment with no radiological issues resulting from the artefacts [23]. These studies are in accordance with De Jong's results [24].

\section{Strengths and limitations}

As the management and treatment strategies of distal radius fractures might differ between institutions and even between treating physicians, our single-centre investigation decreased the chance of including a bias resulting from different treatment strategies. One might argue that the inclusion of type B fractures only might have improved the outcome; however, we feel that the concentration on one specific type entity of fracture reduced the heterogeneity of outcome measures. One limitation of this study was the sample size. It was not designed as a controlled cross-sectional study, and in order to be able to show non-inferiority of this implant compared to routinely used implants a higher sample size would be necessary. However, this study showed the clinical application with a reasonable follow-up period and might therefore serve as groundwork for future research to assess and compare different implants for the surgical treatment of fractures. The histological analysis of only one patient was not representative and should not be generalised. However, since none of the patients showed clinically relevant complications that led to implant removal, we feel that this implant may be safe to use in selected patients.

Further research is needed to assess long-term outcomes as well as comparisons of implant types with larger sample sizes. 


\section{Improvement of Functionality}

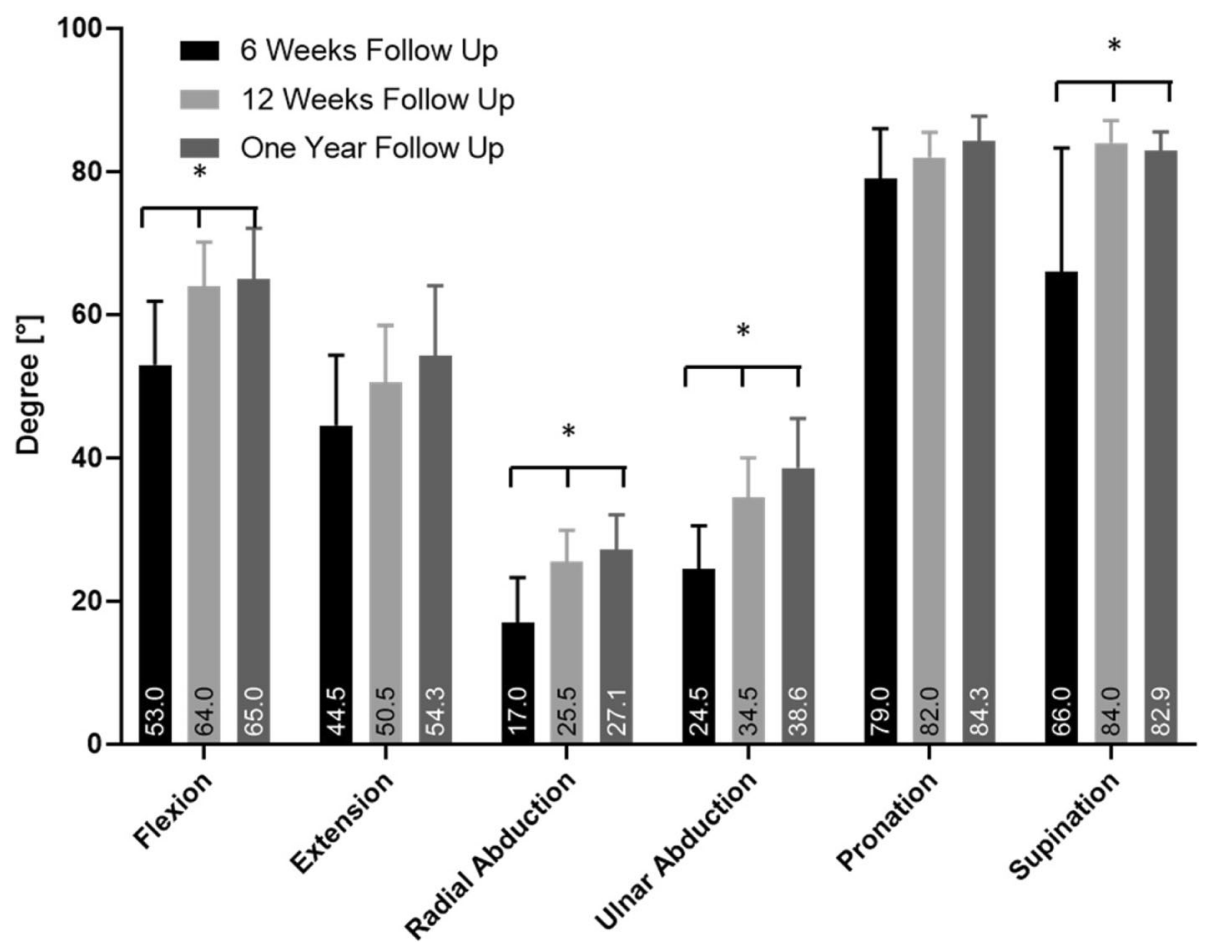

Fig. 4 Improvement of Range of Motion during the Follow up after treatment with $2.7 \mathrm{~mm}$. CF/PEEK distal radius plate. ${ }^{*}=p<0.05$; statistical significant increase in range of motion during follow up period

\section{Conclusions}

Our study showed the clinical and radiological application of CF/PEEK implants in distal radius fractures. We conclude that this implant is safe to use in patients with Btype fractures of the distal radius. Radiologic assessment of fracture union was improved and functional outcome improved significantly over 1 year.

\section{Abbreviations}

AO: Classification system of fractures; CF/PEEK: Carbon-fibre-reinforced polyether ether ketone; PEEK: Polyether ether ketone

\section{Authors' contributions}

All authors have made substantial contributions to the concept and design of the study (FA/TR/HP), acquisition of data (FA/TR), analysis and interpretation of data (FA/SH/TR/HP), drafting the article and revising it critically for important intellectual content (FA/TR/HP), and have given final approval for the version submitted (FA/SH/TR/HP).

\section{Funding}

For the present study, institutional funding was used. There was no influence of other sources on the design of the study and the collection, analysis, and interpretation of data and in writing the manuscript.

\section{Availability of data and materials}

All data generated or analysed during this study are included in this published article. The datasets are not publicly available due to privacy limitations but are available from the corresponding author by reasonable request.
Ethics approval and consent to participate

The study was approved by the local Institutional Review Board and the local Medical Ethical Committee (University Hospital Zürich). General consent was obtained according to the institutional guidelines.

\section{Consent for publication}

General consent was obtained according to the institutional guidelines.

\section{Competing interests}

None of the authors have any conflicts of interests to declare. The authors received no pharmaceutical or industrial support for this study. No further direct or indirect financial support or other assets were transferred to the authors or their family members for this study.

There was no type of support by the industrial producer of the implants used in this study, including grant support, financial reimbursement for travel, speaker fees, stocks and bonds, or any other financial or otherwise relevant relationship with this particular vendor. None of these conflicts exist for any of the authors. We are stating and emphasizing the absence of any conflict in order to avoid any perception of industrial bias.

Received: 6 May 2019 Accepted: 27 August 2019

Published online: 04 September 2019

\section{References}

1. Morrison C, Macnair R, MacDonald C, Wykman A, Goldie I, Grant MH. In vitro biocompatibility testing of polymers for orthopaedic implants using cultured fibroblasts and osteoblasts. Biomaterials. 1995;16(13):987-92.

2. Macnair R, Rodgers EH, Macdonald C, Wykman A, Goldie I, Grant MH. The response of primary rat and human osteoblasts and an immortalized rat osteoblast cell line to orthopaedic materials: comparative sensitivity of several toxicity indices. J Mater Sci Mater Med. 1997;8(2):105-11.

3. Merolli A, Rocchi L, De Spirito M, Federico F, Morini A, Mingarelli L, et al. Debris of carbon-fibers originated from a CFRP ( $p E E K$ ) wrist-plate triggered a destruent synovitis in human. J Mater Sci Mater Med. 2016;27(3):50. 
4. Wenz LM, Merritt K, Brown SA, Moet A, Steffee AD. In vitro biocompatibility of polyetheretherketone and polysulfone composites. J Biomed Mater Res. 1990;24(2):207-15

5. Cao J, Lu Y, Chen H, Zhang L, Xiong C. Preparation, mechanical properties and in vitro cytocompatibility of multi-walled carbon nanotubes/poly (etheretherketone) nanocomposites. J Biomater Sci Polym Ed. 2018;29(4):428-47.

6. Suska F, Omar O, Emanuelsson L, Taylor M, Gruner P, Kinbrum A, et al. Enhancement of CRF-PEEK osseointegration by plasma-sprayed hydroxyapatite: a rabbit model. J Biomater Appl. 2014;29(2):234-42.

7. Wang H, Xu M, Zhang W, Kwok DT, Jiang J, Wu Z, et al. Mechanical and biological characteristics of diamond-like carbon coated poly aryl-etherether-ketone. Biomaterials. 2010;31(32):8181-7.

8. Li CS, Vannabouathong C, Sprague S, Bhandari M. The use of carbon-Fiberreinforced (CFR) PEEK material in orthopedic implants: a systematic review. Clin Med Insights Arthritis Musculoskelet Disord. 2015:8:33-45.

9. Honigmann P, Sharma N, Okolo B, Popp U, Msallem B, Thieringer FM. Patientspecific surgical implants made of 3D printed PEEK: material, technology, and scope of surgical application. Biomed Res Int. 2018;2018:4520636.

10. Orbay J. Volar plate fixation of distal radius fractures. Hand Clin. 2005;21(3):347-54.

11. World Medical A. World Medical association declaration of Helsinki: ethical principles for medical research involving human subjects. JAMA. 2013;310(20):2191-4.

12. Rikli DA, Babst R, Jupiter JB. Distal radius fractures: new concepts as basis for surgical treatment. Handchir Mikrochir Plast Chir. 2007;39(1):2-8.

13. Bagheri ZS, El Sawi I, Schemitsch EH, Zdero R, Bougherara H. Biomechanical properties of an advanced new carbon/flax/epoxy composite material for bone plate applications. J Mech Behav Biomed Mater. 2013;20:398-406.

14. Pesakova V, Klezl Z, Balik K, Adam M. Biomechanical and biological properties of the implant material carbon-carbon composite covered with pyrolytic carbon. J Mater Sci Mater Med. 2000;11(12):793-8.

15. Steinberg EL, Rath E, Shlaifer A, Chechik O, Maman E, Salai M. Carbon fiber reinforced PEEK optima--a composite material biomechanical properties and wear/debris characteristics of CF-PEEK composites for orthopedic trauma implants. J Mech Behav Biomed Mater. 2013;17:221-8.

16. Tarallo L, Mugnai R, Adani R, Catani F. A new volar plate DiPhos-RM for fixation of distal radius fracture: preliminary report. Tech Hand Up Extrem Surg. 2013;17(1):41-5.

17. Osada D, Fujita S, Tamai K, Iwamoto A, Tomizawa K, Saotome K. Biomechanics in uniaxial compression of three distal radius volar plates. J Hand Surg Am. 2004;29(3):446-51.

18. Haher T, Ottaviano D, Lapman P, Goldfarb B, Merola A, Valdevit A. A comparison of stainless steel and CP titanium rods for the anterior instrumentation of scoliosis. Biomed Mater Eng. 2004;14(1):71-7.

19. Prevel CD, Katona T, Eppley BL, Moore K, McCarty M, Ge J. A biomechanical analysis of the stability of titanium bone fixation systems in proximal phalangeal fractures. Ann Plast Surg. 1996;37(5):473-81.

20. Mudrick CA, Owen JR, Wayne JS, Isaacs JE. Unicortical PEEK inset locking fixation for metacarpal fractures: a biomechanical study. Eur J Orthop Surg Traumatol. 2014;24(8):1415-20.

21. Behrendt $\mathrm{P}$, Kruse $\mathrm{E}$, Kluter T, Fitschen-Oestern $\mathrm{S}$, Weuster M, Menzdorf $\mathrm{L}$, et al. Fixed angle carbon fiber reinforced polymer composite plate for treatment of distal radius fractures : pilot study on clinical applications Unfallchirurg. 2017;120(2):139-46.

22. Perugia D, Guzzini M, Mazza D, lorio C, Civitenga C, Ferretti A. Comparison between carbon-peek volar locking plates and titanium volar locking plates in the treatment of distal radius fractures. Injury. 2017;48(Suppl 3):S24-S9.

23. Di Maggio B, Sessa P, Mantelli P, Maniscalco P, Rivera F, Calori GM, et al. PEEK radiolucent plate for distal radius fractures: multicentre clinical results at 12 months follow up. Injury. 2017;48(Suppl 3):S34-S8.

24. de Jong JJ, Lataster A, van Rietbergen B, Arts JJ, Geusens PP, van den Bergh JP, et al. Distal radius plate of CFR-PEEK has minimal effect compared to titanium plates on bone parameters in high-resolution peripheral quantitative computed tomography: a pilot study. BMC Med Imaging. 2017;17(1):18,

\section{Publisher's Note}

Springer Nature remains neutral with regard to jurisdictional claims in published maps and institutional affiliations.

\section{Ready to submit your research? Choose BMC and benefit from:}

- fast, convenient online submission

- thorough peer review by experienced researchers in your field

- rapid publication on acceptance

- support for research data, including large and complex data types

- gold Open Access which fosters wider collaboration and increased citations

- maximum visibility for your research: over $100 \mathrm{M}$ website views per year

At BMC, research is always in progress.

Learn more biomedcentral.com/submissions 